\title{
Facile Synthesis of Monodispersed PdO Nanoparticles within Mesoporous Silica with Sonication
}

\author{
Yeong-Joon Kim, Jun Gill Kang, Sung-Hwan Lim, ${ }^{\dagger}$ and Jae Hee Song:,* \\ Department of Chemistry, Chungnam National University, Daejeon 305-764, Korea \\ ${ }^{\dagger}$ Department of Advanced Materials Science \& Engineering, Kangwon National University, Chuncheon 200-701, Korea \\ \$Department of Chemistry, Sunchon National University, Suncheon 540-742, Korea. *E-mail: j1song@sunchon.ac.kr \\ Received March 24, 2005
}

Key Words : PdO nanoparticles, Mesoporous silica, Sonication

The synthesis and characterization of nanosized materials is an important issue in basic science research as well as in technological applications, as they have their own characteristic optical, electronic, magnetic, and catalytic properties greatly different from the bulk materials. Therefore, considerable effort has focused on the size and shape selective nanocrystal growth using a variety of synthetic methods including templating, electrochemistry, photochemistry, and seeding.

Since powders and films of mesoporous silica have uniform pore diameters in the range of 4-30 $\mathrm{nm}$ and large surface area, ${ }^{1}$ these materials have been a promising template for the growth of various materials including polymers ${ }^{2-4}$ semiconductors, ${ }^{5-9}$ metals, ${ }^{10-14}$ and metal oxides. $^{15,16}$ Extensive efforts have been directed to the formation of metal nanoparticles inside the mesoporous structures via a solution-based infiltration process. Stucky and coworkers reported the preparation of isolated freestanding metal $(\mathrm{Au}, \mathrm{Ag}, \mathrm{Pt})$ nanowires using SBA-15, followed by removal of the silica frame-work. ${ }^{13}$ Chemical vapor infiltration of volatile metal precursors and their subsequent decomposition in the channels of mesoporous silica have been also reported. ${ }^{11,17}$ Recently, a sonochemical method has been utilized for the preparation of SBA-15supported $\mathrm{Ru}$ nanoparticles by irradiating the $\mathrm{Ru}(\mathrm{III})$ mixture with intense ultrasound. ${ }^{18}$ Generally, the confined nanoparticles within the pores of mesoporous silica have shown an improved stability. However, the processes using mesoporous silica have sometimes resulted in poor morphology control and undesired particle formation outside silica surface.

In this note, we describe a simple sonication-assisted synthetic route for the production of highly dispersed and uniform $\mathrm{PdO}$ nanoparticles within the pore channels of SBA-15 without any surface modification outside SBA-15. Most of $\mathrm{PdO}$ nanoparticles were imbedded inside the pores of SBA-15, which was confirmed by the analysis of a series of through-focused transmission electron microscope (TEM) images. $^{19}$

In this study, $\mathrm{PdO}$ nanoparticles were prepared within the pore channels of mesoporous silica since it has been shown that these have catalytic applications in many reactions as well as sensor applications. ${ }^{20-22}$ It has been also reported that
PdO nanostructures are easily converted to $\mathrm{Pd},{ }^{15}$ which has extensive catalytic applications, by $\mathrm{H}_{2}$ reduction process at an elevated temperature.

\section{Experimental Section}

Powder of SBA-15 was prepared using triblock copolymer $\mathrm{EO}_{20} \mathrm{PO}_{70} \mathrm{EO}_{20}$ as a structure-directing template in accordance with a procedure reported in the literature. ${ }^{1}$ The triblock copolymer templates inside the mesopores were removed by calcination at $550{ }^{\circ} \mathrm{C}$ for $5 \mathrm{~h} .80 \mathrm{mg}$ of assynthesized SBA-15 mesoporous silica was dispersed in a $0.1 \mathrm{M} \mathrm{Pd}\left(\mathrm{NH}_{3}\right)_{4} \mathrm{Cl}_{2} 1: 1 \mathrm{v} / \mathrm{v} \mathrm{H}_{2} \mathrm{O}-\mathrm{EtOH}$ solution to incorporate $\mathrm{Pd}\left(\mathrm{NH}_{3}\right)_{4}{ }^{2+}$ species into the channel pores of SBA-15 by exploiting the weak ion-exchange capability. The mixture was ultrasonicated for $2 \mathrm{~h}$ at room temperature by a commercial ultrasonic cleanser (Branson 1510). The white product was filtered, rinsed with deionized water several times, and dried in a vacuum oven overnight. The dried product was calcined in air at $300{ }^{\circ} \mathrm{C}$ for $2 \mathrm{~h}$. The color of the resulting powder was light brown.

\section{Results and Discussion}

Figure 1a shows the low angle X-ray diffraction patterns of as-synthesized SBA-15 and the $d_{100}$ spacing was $9.5 \mathrm{~nm}$. $\mathrm{X}$-ray diffraction patterns of PdO loaded SBA-15 is shown in Figure 1b. The main diffraction peaks indexed as (100), (110), and (200) were well maintained even after the impregnation process of $\mathrm{PdO}$ nanoparticles, which indicates that well-ordered hexagonally packed mesopores of SBA-15 were retained. Furthermore, all diffraction peaks were not shifted even after the loading of PdO nanoparticles with the same $d_{100}$ spacing of $9.5 \mathrm{~nm}$, implying that our two step synthesis was so mild that the incorporation of $\mathrm{PdO}$ nanocrystals did not induce any structural changes of asmade SBA-15. There were several reports on the enlargements of $d$ spacing due to the formation of semiconductor nanoparticles inside the pores of mesoporous silica, ${ }^{8,9}$ implying that the silica channels were physically opened up by the incorporated particles. Recently, Somorjai and coworkers $^{23}$ have shown that $d$ spacing of Pt-imbedded SBA-15 was very similar to that of pristine SBA-15, 


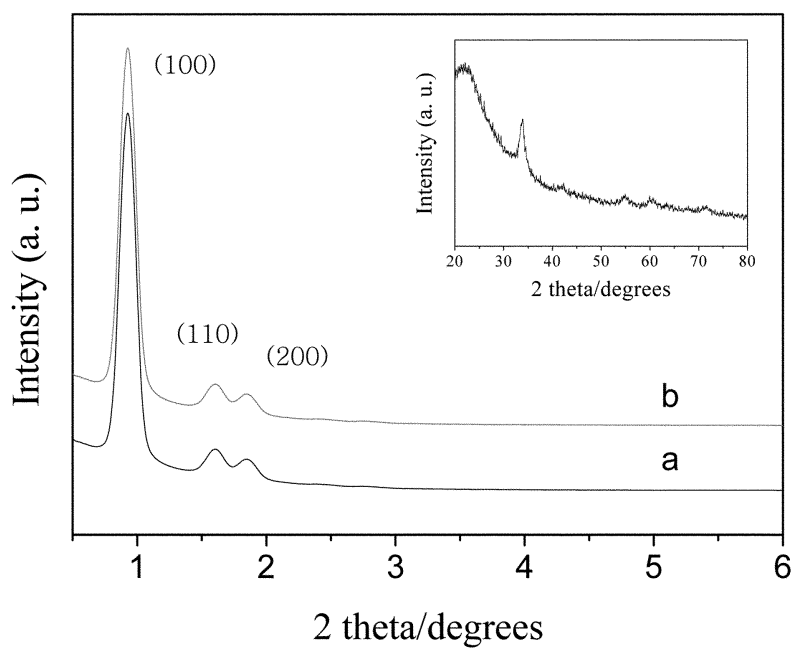

Figure 1. Low angle $X$-ray diffraction patterns of (a) as-made SBA-15 mesoporous silica, and (b) SBA-15 after PdO loading. Inset shows the wide angle X-ray diffraction patterns of SBA-15 after PdO loading.

indicating that the pore channels of mesoporous silica were not disturbed by the inclusion of Pt nanoparticles.

High angle diffraction peaks were observed after the impregnation step of $\mathrm{PdO}$ nanoparticles. From the wide angle X-ray diffraction peaks, $33.9,41.9,54.8^{\circ}$ can be indexed as (101), (110), and (112) faces of the PdO nanoparticles. ${ }^{24}$ (see Figure 1 inset).

TEM image of as-synthesized SBA-15 is shown in Figure $2 \mathrm{a}$ and it shows that the diameters of mesopores of SBA-15 were in the range of 5-6 $\mathrm{nm}$. Figure $2 \mathrm{~b}$ shows the TEM image of PdO loaded mesoporous silica. Extensive formation of highly dispersed and uniform PdO nanoparticles were observed inside the SBA-15 and no bulk aggregation of metal oxide on the external surface of the SBA-15. This result was probably due to sonication-assisted inclusion of metal precursors, $\mathrm{Pd}\left(\mathrm{NH}_{3}\right)_{4}{ }^{2+}$, via a capillary action into the pores of mesoporous silica. A high magnification image of the sample is shown in Figure 2c. A series of throughfocused TEM images around the Scherzer focus of PdO loaded SBA-15 were obtained and it was confirmed that these uniform-sized $\mathrm{PdO}$ nanoparticles were actually imbedded within the pore channels of SBA-15. Without sonication, the production of uniform and highly dispersed nanoparticles was reduced under a similar reaction condition (Figure 2d). This result implies that sonication plays an essential role to promote homogeneous inclusion of $\mathrm{Pd}\left(\mathrm{NH}_{3}\right)_{4}{ }^{2+}$ on the entire silica channels. Sonication-assisted inclusion of nanoparticles into the pores of mesoporous silica has been demonstrated before. Very recently, it was reported that the preformed $\mathrm{Pt}$ nanoparticles could be homogeneously and efficiently incorporated within the silica channels with sonication. ${ }^{23}$ Without sonication, Pt particles were primarily attached on the external surface of SBA-15. Our sonication-assisted reaction process provides a facile and simple preparation of dispersed $\mathrm{PdO}$ nanoparticles inside SBA-15.
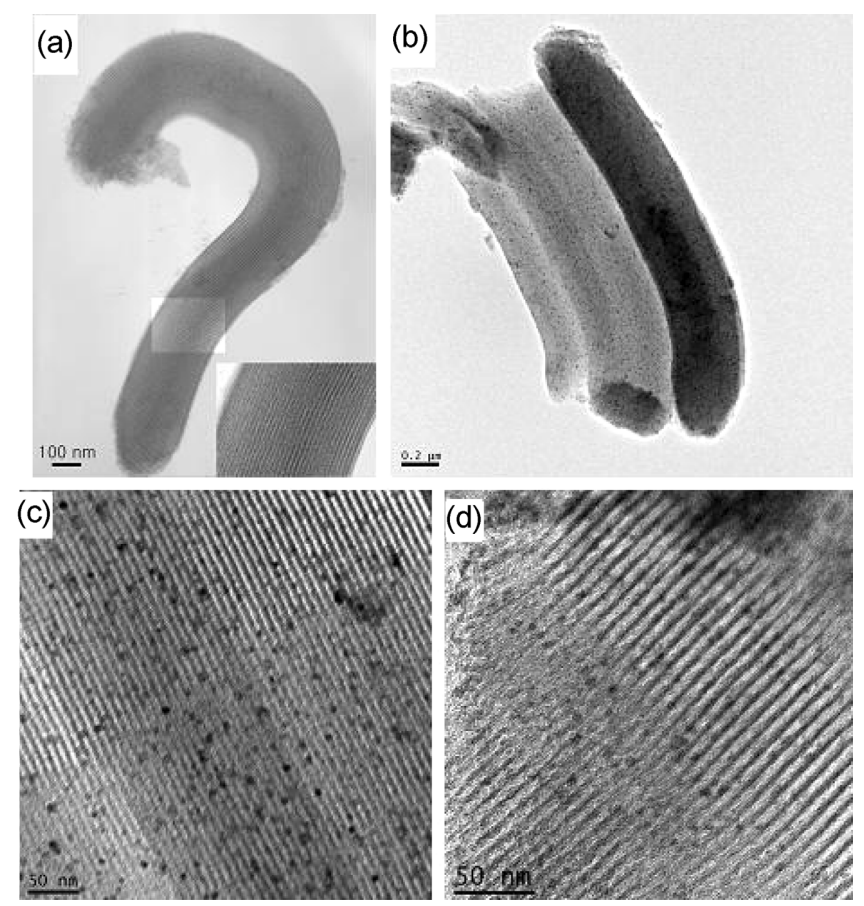

Figure 2. (a) TEM image of as-prepared SBA-15 mesoporous silica. (b) TEM image of SBA-15 loaded with uniform and spherical PdO nanoparticles. (c) High magnification TEM image of PdO nanoparticles inside the SBA-15 mesoporous silica. (d) High magnification TEM image of $\mathrm{PdO}$ nanoparticles inside the SBA-15 prepared without sonication.

This sonication-assisted two step procedure can be utilized to prepare supported highly dispersed catalysts as well as uniform unsupported nanoparticles via dissolution of silica template, since it has been reported that the silica framework was easily dissolved by careful addition of HF to get the unsupported nanocrystals. ${ }^{11,13}$

The composition of the prepared nanoparticles was analyzed by energy dispersive X-ray spectroscopy (Figure 3 ), and the Pd content was 2.1 weight \% within the mesoporous structure.

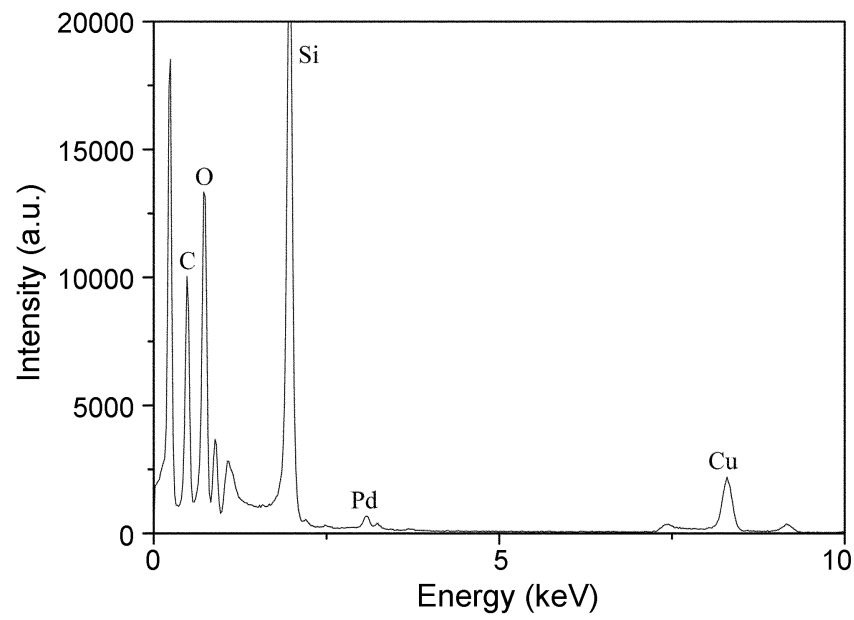

Figure 3. Elemental analysis using energy-dispersive X-ray spectroscopy (EDX). 
In conclusion, using SBA-15 as a size-directing template, highly dispersed and uniform $\mathrm{PdO}$ nanoparticles were prepared via a sonication-assisted process without any surface modification outside SBA-15. PdO nanoparticles were generally spherical and had diameters of 5-6 nm. Most of $\mathrm{PdO}$ nanoparticles were imbedded inside the pores of SBA-15, which was confirmed by the through-focused TEM analysis. Our ongoing project is currently directed to control the diameter of PdO nanoparticles within the pores of SBA15 .

Acknowledgment. This work was supported by the Ministry of Science and Technology of Korea through Proton Accelerator User Program (M202AK0100210A1101-02117) and by Non-directed research funds at Chungnam National University in 2004. We thank Professor S. Chang at KAIST and Mr. J. S. Kim at KBSI for TEM analysis.

\section{References}

1. Zhao, D.; Feng, J.; Huo, Q.; Melosh, N.; Frederickson, G. H.; Chmelka, B. F.; Stucky, G. D. Science 1998, 279, 548.

2. Kageyama, K.; Tamazawa, J.; Aida, T. Science 1999, 258, 2113.

3. Moller, K.; Bein, T. Chem. Mater. 1998, 10, 2950.

4. Johnson, S. A.; Khushalani, D.; Coombs, N.; Mallouk, T. E.; Ozin, G. A. J. Mater. Chem. 1998, 8, 13.

5. Stucky, G. D.; MacDougall, J. E. Science 1990, 247, 669.

6. Srdanov, V. I.; Alxneit, I.; Stucky, G. D.; Reaves, C. M.; Denbaars,
S. P. J. Phys. Chem. B 1998, 102, 3341.

7. Froba, M.; Kohn, R.; Bouffaud, G.; Richard, O.; Tendeloo, G. V. Chem. Mater. 1999, 11, 2858.

8. Wang, S.; Choi, D.; Yang, S. Adv. Mater. 2002, 14, 1311.

9. Zhang, Z.; Dai, S.; Fan, X.; Blom, D. A.; Pennycook, S. J.; Wei, Y. J. Phys. Chem. B 2001, 105, 6755.

10. Huang, M. H.; Choudrey, A.; Yang, P. Chem. Comm. 2000, 1063.

11. Kang, H.; Jun, Y.; Park, J.; Lee, K.; Cheon, J. Chem. Mater. 2000, 12,3530 .

12. Konya, Z.; Puntes, V. F.; Kiricsi, I.; Zhu, J.; Alivisatos, A. P.; Somorjai, G. A. Nano Lett. 2002, $2,907$.

13. Han, Y.; Kim, J. M.; Stucky, G. D. Chem. Mater. 2000, 12, 2068.

14. Zhang, Z.; Dai, S.; Blom, D.; Shen, J. Chem. Mater. 2002, 14, 965.

15. Yuranov, I.; Kiwi-Minsker, L.; Buffat, P.; Renken, A. Chem. Mater. 2004, 16, 760

16. Gu, J.; Xiong, L.; Chen, H.; Ruan, M. Microporous and Mesoporous Mater. 2004, 74, 199.

17. Raja, R.; Sankar, G.; Hermann, S.; Shepard, D. S.; Bromley, S.; Thomas, J. M.; Johnson, B. F. G. Chem. Comm. 1999, 1571.

18. Zhu, S. M.; Zhou, H. S.; Hibino, M.; Honma, I. J. Mater. Chem. 2003, 13, 1115.

19. Lim, S.-H.; Shindo, D.; Yonenaga, I.; Brown, P. D.; Humphreys, C. J. Phys. Rev. Lett. 1998, 81, 5350.

20. McCarty, J. G. Catal. Today 1995, 26, 283.

21. Takeguchi, T.; Takeoh, O.; Aoyama, S.; Ueda, J.; Kikuchi, R.; Eguchi, K. Appl. Catal. A 2003, 252, 205.

22. Content, S.; Trogler, W. C.; Sailor, M. J. Chem. Eur. J. 2000, 6, 2205.

23. Rioux, R. M.; Song, H.; Hoefelmeyer, J. D.; Yang, P.; Somorjai, G. A. J. Phys. Chem. B 2005, 109, 2192.

24. Bi, Y.; Lu, G. Appl. Catal. B 2003, 41, 279. 